https://doi.org/10.52505/filomod.2021.15.43

\title{
PROFILUL CULTURAL ROMÂNESC AL CONCEPTULUI DE FRICA
}

\author{
LILIA TRINCA \\ Universitatea de Stat „Alecu Russo” din Bălţi
}

\begin{abstract}
Rezumat. In lingvistica actuală a devenit deja axiomatic faptul că fiecare limbă naturală reflectă un anumit mod de percepție/conceptualizare și creează propria ,imagine” a lumii. Modul în care emoțiile îşi găsesc reprezentarea lingvistică oglindește un model/grilă de conceptualizare a experienței afective specifice unei culturi. Or, aceeaşi emoţie poate fi experimentată diferit în două culturi diferite sau in cadrul aceleiaşi culturi, putând $f$, deci, obiectul unor variaţii interculturale şi intra-culturale, diacronice şi diatopice.

Ca metodologie de cercetare, pentru relevarea specificului românesc al formelor de manifestare lingvistică a afectelor, în cazul de față FRICĂ, am apelat la date obținute din analiza unităților discursului repetat - proverbe și zicători, frazeologisme, expresii românești - care reprezintă un cod al culturii române, pe baza actualizării lor într-un corpus reprezentativ, care include circa 180 de unități, un set de surse „credibile”, relevante şi reprezentative, care să reflecte emoțile şi modalităţile de expresie afectivă specifice spaţiului cultural român.
\end{abstract}

Cuvinte-cheie: discurs repetat, universalii lingvistice, schemă cognitivă, imagine lingvistică a lumii, model congnitiv-afectiv

Abstract. In current linguistics, it has already become axiomatic that each natural language reflects a certain way of perception/conceptualization and creates its own ,image" of the world. We believe that, in modern conditions of globalization and computerization, the study of the linguistic images of the world is extremely valuable and can gain relevance within the context of the cultures dialogue.

The manner emotions find their linguistic representation mirrors a model/ grid for conceptualizing the affective experience specific to a culture. Still, the same emotion can be experienced differently in two different cultures or within the same culture and can therefore be the object of intercultural and intra-cultural, diachronic and diatopic variations.

As a research methodology, in order to reveal the Romanian specificity of the forms of linguistic manifestation of the affections, in this case FEAR, we resorted to data obtained from the analysis of the units of the repeated discourse-proverbs and sayings, phraseologists, Romanian expressions - which represent a code of the Romanian culture, based on their updating in a representative corpus, which includes approximately 180 units, a set of „credible”, relevant and representative sources, reflecting the emotions and ways of affective expression specific to the Romanian cultural areal.

Keywords: repeated discourse, linguistic universals, cognitive scheme, linguistic image of the world, cognitive-affective model. 
În lingvistica actuală a devenit deja axiomatic faptul că fiecare limbă naturală reflectă un anumit mod de conceptualizare și creează propria,,imagine” a lumii. Emoţiile, după cum afirmă cercetătorul E. Illouz, constituie trăiri individuale, subiective, raportate însă (şi regularizate) la un context social şi cultural mai amplu (Illouz, 2014, p. 221-224). Emoţiile se plasează la interfaţa experienţei individuale, a semnificaţiilor colective şi a constrângerilor sociale (ibid.). Or, afectivitatea este o realitate care se plasează la interfaţa dintre limbaj/limbă şi cultură.

Bibliografia uriașă ce are ca obiect de investigație afectivitatea afectele/ emotiile/sentimentele etc.) configurează o realitate caleidoscopică, ce se poate circumscrie unor domenii diverse: sociologie, psihologie, antropologia culturală, lingvistică, istoria mentalităţilor etc. și generează, implicit, multiple divergenţe de opinie, gravitând preponderent în jurul câtorva trăsături pertinente și definitorii ale afectelor și anume: dimensiunea biologică, socială, antropologică, lingvistică, cognitivă etc.

În lumea științifică se vehiculează ideea că emoţiile constituie un limbaj universal si totuși ipoteza relativității lingvistice - conform căreia sistemele de concepte existente în mintea unei persoane și, prin urmare, trăsăturile esențiale ale gândirii sale sunt determinate de limbajul specific al cărui persoană este ne acreditează ideea că emoţiile sunt construite de parametri socio-culturali.

Ar trebui să facem o precizare cu privire la principala controversă legată de caracterul universal vs. specific cultural al afectivității. Deși aparent dihotomice, aceste două dimensiuni nu se exclud reciproc: existenţa unor emoţii primare universalii afective, recognoscibile transcultural, ce constituie un nucleu cognitiv-afectiv, impregnat în codul genetic universal al oamenilor, găsind lexicalizare în toate limbile lumii nu anulează ideea dependenței şi modelării lor de cadrul socio-cultural în care se actualizează. Or, după cum afirmă cercetătoarea Gabriela Stoica, aceeaşi emoţie poate fi experimentată diferit în două culturi diferite sau în cadrul aceleiaşi culturi, putând fi, deci, obiectul unor variaţii interculturale şi intra-culturale, diacronice şi diatopice (Stoica, 2013, p. 13)

Prin extrapolare, subliniem că și limbajul afectiv, deci expresia lingvistică a afectelor are o funcţie semiotică implicită, fiind dependente cultural. În această ordine de idei, rezultă că și conceptele afective, şi expresia lor lingvistică cunosc o mare varietate transculturală şi lingvistică.

Obiectivul cercetării a fost de a surprinde modul de conceptualizare şi de lexicalizare a emoţiilor şi relevarea modelului cognitiv afectiv specific spaţiului cultural roman în baza câtorva concepte, precum frică, dor, fericire, amar, urât ș.a., întrucât le considerăm circumscrise spaţiului cultural român, având valoare de reper în limba română.

Ca metodologie de cercetare, pentru relevarea specificului românesc al formelor de manifestare lingvistică a afectelor - în cazul de față $\boldsymbol{F R I C ~} \breve{\boldsymbol{A}}$ - am 
apelat la date obținute din analiza unităților discursului repetat - proverbe și zicători, frazeologisme, expresii românești - care reprezintă un cod al culturii române (cf. Noica, Blaga, Stoica etc.), pe baza actualizării lor într-un corpus reprezentativ, care include circa 180 de unităti de discurs repetat, un set de surse „,redibile”, relevante şi reprezentative, care să reflecte emoțiile şi modalităţile de expresie afectivă specifice spaţiului cultural român.

În subsidiar, menționez că, dincolo de faptul că proverbele/zicătorile, frazeologismele sunt universale și se transmit de-a lungul timpului de la un neam la altul, totuși fiecare popor le adaptează după propriile obiceiuri, de aceea reflectă specificul local, istoric și lingvistic. Scurte fraze/sintagme, ce exprimă adevăruri gnomice, în afara timpului istoric, paremiile reprezintă un cod al culturii, așadar constituie adevărate și autentice antologii de bun simț popular, rezultate în urma experiențelor fiecărui popor, fiind reprezentative pentru diferitele limbi.

Frica reprezintă un afect ce are tangențe cu dimensiunea culturală distanţa de putere (din modelul lui Hofstede), care poate implica variaţii ale formelor de manifestare a afectivităţii. Culturile cu o distanţă de putere mare favorizează valori precum conformitatea, obedienţa, autoritatea ierarhică, ceea ce implică o actualizare specifică fricii. În astfel de culturi, se manifestă mai puternic o cenzură emoţională, în vederea menţinerii armoniei ierarhiei sociale sau instituţionale (bunăoară, se evită exprimarea fățișă a dezacordului cu interlocutorul având un statut superior) ${ }^{1}$.

Frica reprezintă un fel de a fi esențial, care ține de existența umana. În mod foarte elocvent, Heidegger a descris faptul că a se teme constituie o formă bazală de existență în lume (după Rotilă, 1997, p. 46). În mitologie, frica era considerată o forţă mai puternică decât oamenii, ce putea fi îmblânzită cu jertfe şi ofrande pentru ca acţiunea ei, ce semăna groază, să se întoarcă asupra duşmanului. Cultivarea fricii în temple şi biserici cu scene de martiraj şi cu picturi despre judecata de apoi au reuşit să înfricoşeze oamenii, care erau învăţaţi că frica este omniprezentă: pe uscat, pe apă, în foc şi la frig. Această cultură era întreţinută prin legendele biblice escatologice ale sfârşitului lumii şi Apocalipsei. Autori precum le Kierkegaard, Dostoevski, Freud, Kafka, Agatha Cristie, Virginia Woolf şi mulţi alţii au mânuit anxietatea de la studiu şi descriere la paroxisme literare, contribuind la decriptarea şi descifrarea anxietăţii umane.

Frica este, fără îndoială, o emoție general-umană. Cu toate acestea, se consideră că fiecare popor interpretează frica într-un mod particular: or, „fiecare popor are, lăsată de Dumnezeu, o faţă proprie, un chip al lui de a vedea lumea şi de a o răsfrânge pentru alţii” (Vulcănescu, 1996, p. 165).

În limba română au existat mulţi termeni pentru frică , iar terminologia specifică: angoasă şi anxietate a fost preluată la începutul secolului al XX-lea (Culturile Greciei antice şi ale Romei au onorat Frica, numind-o angoasă sau anxietate, a cărei etimologie ține de sanscrită: ,amhas”, adică „strâmtoare, îngustare”). Latinii au folosit angusta, termen preluat în franceză şi germană ca angoisse şi angst. Verbul anxiare „, respira dificil”, ,, a se sufoca” şi adjectivul cu sens medical anxios este folosit în documente din secolul al XVI-lea. 
Astfel, se crede că tracii, dacii, popoarele asiatice şi vikingii nu ar fi avut cultul stărilor de frică, iar aceste stări erau atribuite mai ales femeilor şi copiilor, cărora li se inocula ideea că trebuie să moară oricând fără frică. Geto-dacii, conform afirmațiilor cronicarilor antici, nu se temeau de moarte, ba chiar se credeau nemuritori și mergeau să își întâmpine vrăjmașul cu piepturile dezgolite, întrucât credeau în viață veșnică. Teama de moarte, o relevă și filosoful Mircea Vulcănescu în studiul său Dimensiunea românească a existenței, nu e potrivitămentalitătii românești, și asta deosebește poporul român de toate popoarele apusene ${ }^{2}$. Purtarea lui e ancorată-n veșnicie, iar teama de moarte este o meteahnă venită din apus (...). Și această lipsă de teamă în faţa morții este foarte bine pusă în scenă în baladele populare românești, cu toată simbolistica lor, iar Miorița este cea mai elocventă în acest sens: unicul lucru ce îl preocupă când află că i s-a pus gând rău nu e teama de moarte, altfel ar fi luat măsurile elementare de precauție, ci împlinirea ritualului.

Menționăm, în această ordine de idei, și basmele nemuririi la români, ca bunăoară „Tinerețe fără bătrânețe şi viaţă fără de moarte” de P. Ispirescu, care, în viziunea filosofului român C. Noica, exprimă cel mai adecvat fiinţa ca arhetip în versiune românească şi, totodată, contrastul dintre devenirea oarbă - devenirea pentru devenire - şi devenirea cu sens, devenirea întru fiinţă (a se vedea Mamulea, 2015, p. 157).

Ideea o regăsim cristalizată și în mai multe proverbe românești, formule de gândire, care pot conduce la reconstituirea filosofiei populare şi etnosofiei: De moarte nu te teme şi de viaţă nu fi cu grijă; cel de se teme de moarte, aleargă după ea ș. a.

Fără îndoială că globalizarea și occidentalizarea au contribuit la desacralizarea și ruperea de tradiții, fapt ce a schimbat înfățișarea și caracterul românului. El a devenit astăzi la fel de temător precum un occidental, aspect consemnat în expresii precum: Leac de frica $n u$-i; $N$-are de ce lega frica; Tie ti-e frica cu mine că mie mi-a plesnit fierea cu tine; A-i fi frică și de umbra sa; Când te muşcă şarpele, îţi este frică şi de râmă; Iepuraşul nu-i fricos, numai că se cam dă la dos; De sfânt, sfânt să fii, dar de frică tot să ştii; De frică nu vede lumea; Frica e mai mare decât spaima; Frica întotdeauna aduce primejdie; Fricosu' se teme şi de umbra lui; Cel fricos î̀ înfricoşează şi pe alţii; Voinicos, dar cam fricos; Ție ți-e frica cu mine? Că eu am sfeclit-o

2 După Mircea Vulcănescu, sufletul românesc este constituit din două elemente antagoniste: chipul omului de la munte și chipul omului de plai. Mai mult, lupta dintre ethosul păstoresc tracic şi ethosul plugăresc slavo-roman s-a dus de-a lungul veacurilor cu sorţi variabili, până în preajma veacului al XIX-lea, începând din secolul al VIII-lea. Cu secarea pădurilor şi prefacerea României din țară de păstori şi crescători de vite şi din ţară de ostaşi, ethosul păstoresc se pare că cedează în faţa celui plugăresc. Dispare din neam spiritul de aventură, spiritul culmilor, al zărilor îndepărtate, al adâncimilor amare pentru omul orizontului mic de sat, fricos şi aşezat (Vulcănescu, 1997, p. 193). 
cu tine! Omul fricos totdeauna umblă cu gheaţa-n sân, $A$ duce frica cuiva (sau a ceva) ${ }^{3}$ ș.a.m.d.

Adesea frica îl forțează pe român să fie cinstit, să respecte norma/legile: Frica păzeşte pepenii/harbuzăria/bostănăria ; Cerul curat de trăsnet nu se teme ș. a.

Românul vede curajul drept o consecință a fricii: Curajul este capacitatea de a te purta așa cum trebuie chiar si atunci când ești pe jumătate mort de frică ș. a.

Odată cu apariţia instituţionalizată a religiei, teama generată de moarte, trecerea implacabilă a timpului, precum și fatalitatea devine adesea motiv de ritual, ceea ce pornește dinspre un complex de inferioritate a mentalului colectiv în faţa unei naturi neînţelese. Aceasta implică popularea imaginarului român colectiv cu reprezentări puternice ale divinităţii ,,alături de ciclurile de timp trăit în mod subiectiv de individ - instabil, schimbător, ducând însă inexorabil la bătrâneţe şi la moarte, timp trăit cu răsturnările sale bruşte, cu capriciile sale imprevizibile, cu ireversibilitatea sa angoasantă" (Ivancu, 2013, p. 87): Cf. De ce ti-e frica, de aceea nu scapi! Cine vede că arde casa vecinului, trebuie să aibă frică de a sa; De frica nu se descântă; Unii mor mai mult de frică decât de boală ș. a.

Totuși românul interpretează frica drept o emoție denigradoare, apariția ei fiind justificată, întrucât e specifică celui vinovat în fond: Omul de vină se teme și de umbră; Cine se tot teme, nimica nu face; Curaj de oaie: mereu cu nasul în jos; Să nu meargă în pădure cine are frică de frunze; Fricosul este pe jumătate îvins; Hotului de hot îi e fric; Ura, zavistia şi frica nasc vicleşugu; Omul nedrept se teme de toţi ș. a.

Adesea românul ironizează pe seama emoției de frică: Fricosul se teme şi de toate buruienile; I-e frică să nu i se răcească cuibul; Cine mai mult se teme, acela uită uşa deschisă ; Până la luptă face gură şi-apoi se teme dempuşcătură; Mai ştie sfântul şi de frică; Nu merge la soare de frică să nu $i$ se topească nasul; Dobitocului îi este frică de bici, omului - de cuvânt, iar indărătnicului - nici de una, nici de alta; De securea fără coadă n-are frică pădurea; Daca aduni toată viața bani de frica sărăciei, ai ajuns deja sclavul ei; $N$-are de ce lega frica; $A$-i tremura chiloții de frică (argotic) ș. a.

Frica îl face pe cel pățit mai precaut. După afirmația lui O. Ivancu, ,individual, românul e în permanenţă ezitant atunci când vine vorba de acţiuni importante, semnificative. El devine în felul acesta vulnerabil pentru că „,nehotărâtul trăieşte în permanenţă în orizontul regretului, al unui dublu regret. Într-un fel, el anticipează regretul pe care l-ar cunoaşte acţionând şi

${ }^{3}$ Ai prevăzut şi ai ascuns banii, de frică. Ştii dumneata unde duce frica? La panică şi la perturbare. (Tudor Arghezi).

${ }^{4}$ Până l-am dat la brazdă, mi-am stupit sufletul cu dânsul. Numai eu îi vin de hac. Vorba ceea: „Frica păzeşte bostănăria” (Ion Creangă). 
care în fapt, el tocmai, îl face să nu acţioneze" (Ivancu, 2013, p. 142). Iată câteva proverbe care vin să confirme aceste constatări: Pe cine l-a ars păsatul suflă și în apă rece. Cine s-a ars cu ciorba suflă și în iaurt.

Frica este asociată de români cu animale/insecte și anume: Nicio frică de furnică de țânţar - nici habar; De frică îi pare cuşma pisică ca tiganului de albină; $S$-ar duce in pădure, dar se teme de şarpe; Laşul poartă şi frică de furnică; De s-ar teme lumea de vrăbii, n-ar semăna mălai; Meşterul strică şi drege de frică; Cine e muscat de șarpe se pazește/se teme si de șopârlă; Frica face iepurele să cadă; Pisica opărită se teme de rece; Oile ţin capu-n jos de frică să nu le vadă lupu; Dacă ți-e frică de lup, nu intri în pădure; Dacă lupul s-ar teme de ploaie, ar purta manta; Vulpea nu se teme de vânătorul care se laudă seara ș. a.

Am remarcat și câteva proverbe care consemnează de ce nu e cazul să-ți fie frică: Cutea vârtoasă nu se teme de coasă; Baba bătrână nu se teme de pâinea moale; Săracul nu se teme de tâlhari; Nu se ştie frica decât de boală ș.a.

Consemnăm și câteva expresii frazeologice somatice ce fac referință la conceptul de frică: A avea (a fi cu) inima aproape de gură; A băga (cuiva) frica în oase ${ }^{5}$; A fi cu frica în spate (sau în sân) ${ }^{6} ; A$ şti de frica cuiva ${ }^{7}$ ș. a.

Astfel, frica se asociază cu o temperatură scăzută: a-i îngheţa cuiva sângele în vine, $A$-i îngheţa cuiva ficaţii, imagine pe care o regăsim întocmai și în limba rusă, engleză, franceză etc., ceea ce indică universalitatea conceptualizării fricii: $C f$. rus. Кровь стынет в жилах; Кровь леденеет (холодеет) в жилах; engl. To be frozen with fear, fr. Etre glacé de peur / d'effroi etc.

Şi limba este organul care are tangențe cu frica ${ }^{8}$, iar în cadrul expresiilor frazeologice somatice, ilustrează conceptul emotiv de frică atât în limba română, precum și în alte limbi: (a-şi pierde graiul de frică) vs. rus. языı отнялся, fr. rester coi.

Mai mult, frica are și culoare la români - galbenul: A se ingălbeni de frică. (Cf. fr. blêmir de peur) ${ }^{9}$.

Bineînțeles, studiul unităților ce aparțin discursului repetat plasează analiza modelelor cognitiv-afective românești pe un fundal cultural specific unei perioade istorice mai vechi (majoritatea unităților discursului repetat având o vechime de secole). Dimensiunile culturale relevate în modelul

${ }^{5}$ Iar Sisoe, ca să-i vâre şi mai tare-n oase frica de cele dumnezeieşti, se stropşi la dânsul umflându-şi obrajii, ba se şi luă după el câţiva paşi, cu toiagul ridicat. (G. Topârceanu).

${ }^{6}$ Bătrâna, cu frica Domnului în sân, crezu. Se sperie văzându-şi fata sângerată. (Barbu Delavrancea).

[...] oamenii lui Marmont începură să-mi ştie de frică şi mă pomenii vânat cu inverşunare de duşmanul care pornise asupra mea o hăituială în toată puterea cuvântului. (Octavian Soviany)

${ }_{9}^{8}$ Pentru detalii a se vedea V. Lifari.

Când îl văzu, muierea înlemni şi îngălbeni de frică. (P. Ispirescu). 
propus de Hofstede, precum individualism/colectivism, sine independent/ sine interdependent etc. sunt variabile diacronic, determinând şi schimbări ale reprezentării conceptuale şi lingvistice a vieţii afective. Astfel, mutaţii esenţiale privind modalitatea de configurare a sinelui, produse ca rezultat al schimbărilor social-culturale mai ample, va reconfigura imediat şi modalitatea de conceptualizare afectivă. Prin urmare, modernizarea societăţii (angrenând un proces de individualizare, emancipare treptată a individului) implică o redefinire a trăirilor afective.

După cum se cunoaște, trăsătura fundamentală a culturii române este interferenţa, fuziunea organică între modelul cultural de tip tradiţional, orientalbalcanic şi cel nou, modern-occidental; Această suprapunere a două tipare mentale dihotomice în aparenţă, de facto a generat o întrepătrundere armonioasă, când anume aspecte ale culturii occidentale se grefează pe o matrice culturală locală de tip clasic şi popular-tradiţională, generând o configuraţie culturală sui generis, unde coexistă vechiul şi noul, orientul, tradiţionalul şi modernul. De aceea, pentru a ne sincroniza cu mutaţiile contextului extralingvistic, pe care se proiectează, justificând variaţiile diacronice de codare lingvistică a conceptelor afective, am recurs în cercetare la corelarea dimensiunii cognitive şi a celei culturale, pentru evidențierea particularităților de codare lingvistică a conceptelor afective. Paradigma teoretică mai amplă în care se situează cercetarea este, în general, cea a cognitivismului, ceea ce conferă accesul la structuri şi scheme cognitive implicate în conceptualizarea emoţiilor.

În acest scop, am apelat la datele Dicționarului asociativ al limbii române ${ }^{10}$, adunate prin metoda experimentului asociativ (elaborată în psiholingvistică). Astfel, rețelele pragmatice şi asociative ale semnificaţiilor în care este antrenat fiecare cuvânt ce desemnează o emoţie sunt deosebit de bogate. Sensul complex al fiecărui cuvânt de acest fel este rezultatul rolului important pe care aceste cuvinte îl joacă în articularea unei palete întregi de valori culturale, relaţii sociale. Premisa de la care am pornit este că un asemenea studiu poate reflecta dinamica conceptual-istorică a unui anume model cognitiv afectiv specific unei culturi.

Pentru relevarea specificului românesc al conceptului de frică am apelat și la datele stocate în Dicționarul asociativ al limbii române, adunate prin metoda experimentului asociativ (în continuare EA) elaborată în psiholingvistică - o disciplină de frontieră, care încearcă să fundamenteze legătura între procesele neuropsihice, lumea gândirilor şi exprimarea verbală a acestora, între conştient şi inconştient, în vederea surprinderii mecanismelor reprezentării prin identificarea proceselor prin intermediul cărora are loc cunoaşterea. Studiile în domeniul psiholingvisticii relevă relativitatea lingvistică şi cea culturală: or, din perspectivă fenomenologică, limba şi logica exprimată prin aceasta, reprezintă un factor extrem de important pentru

${ }^{10}$ Gh. Popa et alii, Dicționarul asociativ al limbii române, vol. I (de la stimul la reacție), Iași, Editura Junimea, 2016. 
înțelegerea şi reprezentarea lumii înconjurătoare. E, într-un fel, o evoluţie a ,ipotezei Sapir-Worf”, conform căreia diferite tipuri de mentalităţi antrenează diverse modelaje ale limbajului ${ }^{11}$.

În baza EA realizat, am identificat două tipuri de bază de asociaţii pentru cuvântul-stimul teamă: asociaţii sintagmatice şi asociaţii paradigmatice ${ }^{12}$ :

ASOCIAŢII PARADIGMATICE:

- Sinonime: frică (468); spaimă (25); groază (4); anxietate (3); fobie (3); emoție (2); teroare, claustofobie;

- Antonime: cura Asociații: durere (7), nesiguranță (5), singurătate (5), examen (4), slăbiciune (4), neîncredre (4), tremur (3), pericol (3), tristețe (3), necaz (2), necunoscut (2), noapte (2), nou (2), pedeapsă (2), plăcere (2), plans (2), sentiment (2), stress, (2), supărare (2), ură (2), moarte, boală, gol in stomac;

- Animale sau insecte/ vietăți: șarpe (5); șerpi (3), câine (4); câini (4); insecte (2); emoție (2); animal, arici, căprioară, lupi, furnică, tigru, șoareci, păianjen ${ }^{13}$;

- Obiecte ce determină apariția fricii: întuneric (23), fantome (3), moarte (2), tunet, impozit, școală, examen, boală, monștri, primejdie, necunoaștere, umbră, țipăt, violență, bătrânețe;

ASOCIAŢII SINTAGMATICE:

- mare (9), grea (4), negru (3).

Cauze ce provoacă frica: de întuneric (4), de moarte (2), de câine, de Dumnezeu, de lupi, de singurătate, de apă, de rău etc.

${ }^{11}$ Am efectuat un EA liber cu tineri cu vârsta cuprinsă între 18-25 de ani, pentru care limba maternă este româna. Respondenţii au fost rugaţi să răspundă instantaneu cu primul cuvânt care le-a venit în minte la auzul cuvântului-stimul teamă (fiecare anchetă propusă conţinea 100 de cuvinte-stimul, selectate şi generate de calculator din circa 500 de stimuli, ce fac parte din nucleul şi masa vocabularului de bază al limbii române: stimulul teamă apare, în medie, în una din 5 anchete). Or respectarea acestei condiţii în timpul anchetării permite a reduce la minim intervalul temporal dintre stimul şi reacţie: respondentul nu trebuie să mediteze asupra reacţiei, întrucât conceptul de asociaţie exclude ideea de „gândire” a răspunsului. În calitate de respondenţi au fost circa 1000 de studenţi din mai multe universităţi din Republica Moldova şi România. Trebuie de menţionat că factorul determinant pentru alegerea studenţilor în calitate de respondenţi în cadrul EA revine faptului că la vârsta de 17-25 de ani se produce deja formarea identităţii lingvale, iar asociaţiile, identificate în cadrul EA, reflectă competenţa lingvistică şi sunt relevante pentru mentalul român (Караулов, p. 192). În conformitate cu opinia lui Iu. Karaulov, stabilitatea relativă a capacităţii lingvistice a vorbitorilor nativi (de exemplu, vocabularul, ierarhia de valori, valenţele lexicale) poate servi drept bază pentru descrierea conştiinţei de masă în societatea românească în următorii 20-30 de ani, adică pentru perioada cînd respondenții de azi vor constitui nucleul activ al societăţii (ibidem).

${ }^{12}$ Respectând tradiţia modelării câmpului asociativ, la început se prezintă cuvintelereacţii ce apar mai des (numărul reacţiilor e indicat între paranteze), constituind nucleul câmpului asociativ, după care se indică cuvintele apărute mai rar ca reacţii la stimulul respectiv - periferia câmpului asociativ.

${ }^{13}$ După cum se poate vedea, multe din ele sunt reperabile și în unităţile DR. 
O reacție foarte relevantă la cuvântul-stimul teamă, pentru spiritul roman, este $\mathbf{N u}$ există, întrucât vine în consonanță perfectă cu ideea filosofului român Mircea Vulcănescu, care menționează câteva atitudini fundamentale ale românului în fața existenței. În primul rând, pentru român nu există ideea de neant, apoi nu există imposibilitatea absolută, nu există alternativa existențială, nu există imperativ, nu există iremediabil, și cel mai important aspect, nu există teamă în fața morții - sentimentul ancorării în veșnicie $\hat{\imath} l$ salvează pe român în cele mai disperate situații, cum îi pune aripi de plumb in împrejurările nesperat de favorabile, cu care aripa sorții nu l-a atins prea des (Vulcănescu, 1996, p. 193).

Concluziile la care am ajuns ca rezultat al investigației dovedesc faptul că experienţa emoțională nu este pre-culturala, ci proeminent culturala: emoţiile servesc unor scopuri de comunicare complexă, de ordin moral şi cultural. Emoțiile, așadar, nu constituie simple etichete pentru stări interioare, a căror esență este presupusă a fi universală. Este incontestabil faptul că emoţiile sunt forme de acțiune simbolică cu multiple articulaţii la nivelul culturii şi al structurilor sociale. Aplicarea metodei EA ne-a permis elucidarea bogăţiei „sarcinilor" semantice, pe care le poartă conceptul de „frică” în română. Asociaţiile identificate prin intermediul EA permit decodificarea şi construirea asemenea unui puzzle, a semnificaţiilor conceptului dat prin angajarea atât a componentei cognitive, cât şi a celei afective - procese simultane, dar şi complementare, limbajul fiind o cale preferenţială în tentativa de a releva modul în care e organizată şi stocată cunoaşterea în mintea umană.

\section{Referințe bibliografice: Cărti si website-uri:}

- HOFSTEDE, G., 1984, Culture's Consequences: International Differences in Work-Related Values, Sage, Beverly Hills.

- ILlOUZ, E., GILON, D., SHACHAK, M., 2014, "Emotions and Cultural Theory", în Stets, J. E., Turner, J. H. (eds.), Handbook of the Sociology of Emotions, vol. II, Dordrecht, Springer, pp. 221-244.

- IVANCU, Ovidiu, Identitate culturală şi mental colectiv românesc în postcomunism (1990-2007) - Imagini, mituri, percepţii, repoziţionări, Cluj-Napoca, Editura EIKON, 2013.

- LIFARI, Viorica, Categoriile conceptuale ale emotiilor redate prin ,imaginea organelor interne omeneşti" descrise în expresii frazeologice somatice //

http://studiamsu.eu/nr-10-100-2016/

http://dspace.usm.md:8080/xmlui/handle/123456789/1182.

- MAMULEA, Mona, Teme filosofice în cultura populară românească, Bucureşti, Editura Academiei Române, 2015, p. 157. 
ROTILĂ, Viorel, Heidegger şi rostirea fiinţei, 1997 https://www.academia. edu/11306925/Heidegger_\%C8\%99i_rostirea_fiin\%C8\%9Bei p. 46.

- STOICA, Laura Gabriela, Modele ale afectivității în cultura română premodernă (1780-1840), Lucrare realizată în cadrul proiectului „Cultura română şi modele culturale europene cercetare, sincronizare, durabilitate”, cofinanţat din FONDUL SOCIALEUROPEAN prin Programul Operaţional Sectorial pentru Dezvoltarea Resurselor Umane 2007-2013 // ttps:// www. researchgate.net/publication/317038418_Modele_ale_afectivitatii_in_cultura_romana premoderna_1740-1840_Models_of_Affectivitity_in_the_Early-Modern_Romanian Culture 1740-1840

- VULCĂNESCU, Mircea, Către ființa spiritualității românești. Vol. III. Dimensiunea românească a existenței, București: Editura Eminescu, 1996.

\section{Dicționare:}

- DUDA, Gabriela, GUGUI Aglaia, Wojcicki, Marie Jeanne. Dicţionar de expresii şi locuţiuni ale limbii române, Bucureşti, Editura Albatros, 1985.

- ILINCAN, Vasile, Dicționar de expresii românești în contexte $(D-N)$, Presa Universitară Clujeană(DERC) http://www.editura.ubbcluj.ro/bd/ebooks/pdf/1969.pdf

- POPA, Gheorghe; SAINENCO, Ala; PRITCAN, Valentina; POPA, Viorica; LACUSTA, Elena; TRINCA, Lilia, POPA Lucia. Dicţionarul asociativ al limbii române, Iaşi: Junimea, 2016.

- TOMICI, Mile. Dicționar frazeologic al limbii române, Editura Vestala Saeculum Dicționar de proverbe și zicători românești/ alcătuit, pref. de Grigore Botezatu și Andrei Hâncu; col. iniț. și coord. de Anatol și Dan Vidrașcu. - București; Chișinău, Editura Litera, 2001.

- ZANNE, Iuliu. Proverbele românilor, Editura Librăriei Socec, Bucureşti, 1895. Dicționar de proverbe și zicători românești/ alcătuit, pref. de Grigore Botezatu și Andrei Hâncu; col. iniț. şi coord. de Anatol și Dan Vidrașcu. - București; Chişinău: Litera, 2001 (Combinatul Poligrafic).

- КАРАУЛОВ Ю. Н., Русский ассоичативный словарь как новый лингвистический источник и инструмент анализа языковой способности. і̂n Русский ассоциативный словарь. Книга 1. Прямой словарь: от стимула к реакции. Ассоциативный тезаурус современного русского языка. Часть I / Ю. Н. Караулов, Ю. А. Сорокин, Е. Ф., Тарасов, Н. В., Уфимцева, Г. А., Черкасова, Москва, Изд-во «Помовский и партнеры», 2011. 